\title{
Publicidade e Infância: a influência dos jingles dos anos 80 e 90
}

\author{
André Luiz Vailati \\ Camila Bergonci Moura²
}

Resumo: A publicidade em forma de música ilustra sonoramente produtos e serviços de forma alegre e descontraída. Os jingles publicitários, na sua essência, possuem letras e melodias simples para que sejam facilmente memorizadas e reverberarem no inconsciente das pessoas. Diante disso, este trabalho tem como objetivo analisar a percepção de pessoas nascidas nas décadas de 1970 e 1980 em relação aos jingles das décadas de 1980 e 1990. Em uma pesquisa de campo de viés descritivo com uma abordagem qualitativa, foram utilizados autores das áreas da publicidade e sociologia para compor o arcabouço teórico. Os resultados revelaram que os jingles trazem consigo mais do que uma finalidade exclusivamente persuasiva, mas também um significativo impacto emocional, perdurando de forma singular na memória dos consumidores.

Palavras-chave: Infância. Memória. Publicidade. Jingle.

Abstract: Advertising in the form of music sonorously illustrates products and services in a cheerful and relaxed way. Advertising jingles, in their essence, have simple lyrics and melodies so that they are easily memorized and reverberate in people's unconscious. This paper aims to analyze the perception of people born in the 1970s and 1980s in relation to the jingles of the 1980s and 1990s. In a descriptive field research with a qualitative approach, authors from the publicity and sociology compose the theoretical framework. The results revealed that jingles carry more than purely persuasive purpose, but also a significant emotional impact, lasting in a unique way in the memory of consumers.

Keywords: Childhood. Memory. Advertising. Jingle.

Resumen: La publicidad en forma de música ilustra sonoramente productos y servicios de forma alegre y relajada. Los jingles publicitarios, en su esencia, poseen letras y melodías sencillas para que sean fácilmente memorizadas y reverberan en el inconsciente de las personas. En este sentido, este trabajo tiene como objetivo analizar la percepción de personas nacidas en las décadas de 1970 y 1980 en relación a los jingles de las décadas de 1980 y 1990. En una investigación de campo de vies descriptivo con un abordaje cualitativo, se utilizaron autores de las áreas de la región, la publicidad y la sociología para componer el marco teórico. Los resultados revelaron que los jingles traen consigo más que una finalidad exclusivamente persuasiva, pero también un

'Universidade do Vale do Itajaí (UNIVALI). Publicitário, doutorando em Educação pela Universidade do Vale do Itajaí (UNIVALI).

¿Universidade do Vale do Itajaí (UNIVALI). Publicitária, graduada pela Universidade do Vale do Itajaí (UNIVALI) 
significativo impacto emocional, perdurando de forma singular en la memoria de los consumidores.

Palabras clave: Infancia. Memoria. Publicidad. Jingle.

\section{Introdução}

A Revolução Industrial incentivou o desenvolvimento de grande parte das atividades publicitárias, nas quais a sociedade de consumo exerceria notável papel de receptora no processo comunicacional. Porém, mesmo com os conglomerados de massa, diferentes públicos necessitaram de estratégias particulares para uma efetiva transmissão da mensagem. Inevitável, por conseguinte, o desenvolvimento de técnicas que influenciariam os processos de comunicação mercadológica. Para Sampaio (2003), a criatividade, a emoção, interesse, pertinência e compreensão são os princípios básicos que necessitam ser atendidos por meio da propaganda.

Nesse processo evolutivo, a publicidade em forma de música obtém significativa relevância, principalmente após o advento do rádio. Os jingles publicitários, produzidos com a intenção de fixar musicalmente a marca e/ou seus benefícios na mente dos consumidores, viriam a facilitar o processo de persuasão. Como explica Sampaio (2003, p. 72):

\footnotetext{
A grande vantagem do jingle é que, por ser música, acaba tendo um expressivo poder de "recall", pois é aquilo que a sabedoria popular chama "chiclete de orelha". As pessoas ouvem e não esquecem. Assobiam ou cantam, mas guardam o tema consigo. O jingle é algo que fica, como provam as peças veiculadas durante um período e tiradas do ar, mas que muitos e muitos anos depois ainda são lembradas pelos consumidores.
}

O primeiro jingle brasileiro nos remete à década de 1930, apresentando "os serviços de uma padaria e foi ao ar no Programa Casé, coordenado por Ademar Casé, na Rádio Phillips" (ALVES, FONTOURA, ANTONIUTTI, 2008, p. 203). Desde então, a publicidade brasileira foi agraciada com inúmeros anúncios musicados que se destacaram nas mídias sonora e televisiva, principalmente pelas técnicas com fundamentos na psicologia que começavam a ser estrategicamente utilizadas. Calazans (2006, p. 107) expõe que

no Brasil, em 1989, Zé Rodrix produziu um jingle para o Chevrolet da General Motors, cujo ritmo era de 80 ciclos por minuto. Segundo Zé Rodrix, o ritmo do coração de uma mãe amamentando o filho, ouvido pelo recém-nascido, é um som associado a conforto, tranquilidade, segurança e prazer.

A revisão da literatura com investigações recentes envolvendo jingles revela um foco na análise da estrutura ou da letra, ou seja, a maioria das pesquisas possui como objeto de estudo a composição textual dos próprios jingles, muitas das vezes os de caráter político. Oportuno, então, o direcionamento à maneira com a qual os consumidores se sentem ao relembrar jingles veiculados há vários anos, com vistas a compreender melhor a influência da publicidade em forma de música e o tempo durante o qual esses jingles podem persistir nitidamente na mente das pessoas.

Levando em consideração a natureza psicológica da persuasão publicitária, a pergunta que orienta o presente estudo é: "Qual a percepção das pessoas nascidas nas décadas de 70 e 80 com relação aos jingles das décadas de 80 e 90?”. A partir desse questionamento, 
definiu-se como objetivo geral desta pesquisa analisar a percepção dos consumidores com relação aos jingles veiculados nas décadas de 1980 e 1990. Como objetivos específicos, foram definidos: perceber a capacidade de lembrança dos jingles veiculados na infância dos entrevistados; identificar os sentimentos dos consumidores ao escutar os jingles; e descobrir hábitos de consumo de mídia sonora na época na qual eram crianças. Assim, este trabalho está dividido em quatro seções: fundamentação teórica, procedimentos metodológicos, análise dos dados e discussão dos resultados e considerações finais.

\section{Memória, Infância e Publicidade}

A percepção da linguagem audiovisual se apresenta como fenômeno relacionado ao universo interior do receptor e costuma ser qualificada como algo individual. Rodriguez (2006) traz. em sua obra, duas visões sobre a percepção da mensagem visual: aqueles que estudam a comunicação em massa, que trabalham com entendimento que cada sujeito percebe e interpreta de modo diferente e individualizado dos outros sujeitos o conjunto de fenômenos que constituem uma mensagem audiovisual; e a visão da psicologia sobre percepção, que comprova sistematicamente que diante de estímulos idênticos as pessoas coincidem com suas percepções. O autor explica a diferença entre a percepção e o reconhecimento das formas sonoras:

A percepção é anterior ao reconhecimento. Perceber formas sonoras significa experimentar sensações subjetivas associadas a estímulos acústicos complexos, antes de atribuir a essas formas algum sentido ou algum valor expressivo. Contrariamente, reconhecer formas sonoras é identificar sensações auditivas já conhecidas às quais estão associadas determinadas relações de contiguidade e de sentido (RODRIGUEZ, 2006, p. 168 e 169).

O autor afirma, ainda, que a interpretação das formas sonoras varia de cada pessoa, com base no que ela associa em relação a seu histórico auditivo. Ou seja, nas experiências que cada indivíduo vivenciou, cada som registrado em sua memória. "Se não existisse uma forma de armazenar mentalmente os fatos do passado, as propagandas não fariam sentido nenhum para os consumidores. A partir da memória, é possível armazenar informações das propagandas e evocá-las quando necessário" (PÉREZ-NEBRA; SANTANA, 2008, p. 14).

O resgate da memória afetiva é fundamental no nosso processo de desenvolvimento psicológico, de autoconhecimento e desenvolvimento pessoal. Segundo Calazans (2006, p. 102),

A memória auditiva envolve a habilidade de armazenar e de evocar o material auditivo. A memória sonora também está ligada aos lugares, aos objetos e aos períodos da vida. A cada nova ocorrência do mesmo som-fonte, a memória recuperará todo um conjunto de experiências acumuladas para dar um novo sentido ao que está sendo ouvido. A publicidade se utiliza dessa memória aproveitando para transmitir segurança aos indivíduos

Nesse aspecto, as análises envolvendo memória e publicidade se tornam ainda mais relevantes se considerarmos a peculiaridade do público infantil, já que suas noções de realidade estão em formação. De acordo com Pacheco (2002), a criança identifica logomarcas antes de ser alfabetizada, mostrando desde os primeiros anos de vida um potencial para absorver informações/mensagens promocionais.

Entre as décadas de 1970 e 1980, com a popularização da televisão, a publicidade brasilei- 
ra assumiu a consolidação do público infantil e, "desde então, ações diretas e indiretas buscam seduzir a criança e torná-la consumidora de bens e serviços" (SOUZA JÚNIOR; FORTALEZA; MACIEL, 2009, p. 22). Publicitários começaram a estudar a maneira mais eficaz para chamar a atenção do público infantil, descobrindo que as crianças preferem "comerciais com humor, irreverentes, inusitados ou que mostram um jeito alegre ou "desencanado" de ser; nada de muito complicado: elas valorizam ideias simples, claras, contadas de forma surpreendente e irreverente, geralmente com final feliz" (PACHECO, 2002, p. 140).

Conforme Souza Júnior, Fortaleza e Maciel (2009), em 1952 foi veiculada a primeira propaganda com um elenco infantil no Brasil. Até a década de 1980, essa participação se limitou a campanhas de produtos alimentícios. contudo, com o passar dos anos, crianças começaram a vender produtos e serviços de outros segmentos, sob quatro principais razões para sua presença na mídia:

1) a criança ouve outra criança, ou seja, ela é particularmente sensível à interpelação de outra criança; 2) a criança tem um forte apelo emocional ou, nas palavras do criativo, ela tem um "apelo mágico" que emociona o adulto e o sensibiliza; 3) a criança pode contribuir para o rejuvenescimento da marca; 4) a criança tem empatia com os anunciantes, favorecendo a aprovação dos comerciais (SAMPAIO, 2000, p. 152).

Nesse cenário, aparecem os jingles publicitários, compostos metodicamente para cativar sua audiência. Geralmente são curtos, não passando de trinta segundos, com letras e melodias compreensíveis para que sejam facilmente memorizadas e recordadas por quem as ouve. Figueiredo (2005, p. 111) conceitua os jingles como "peças cantadas compostas especialmente para a marca anunciante. Sua melodia costuma ser simples e cativante, fácil de ser repetida e cantarolada pelo ouvinte"

A melodia deve ser atraente para facilitar a memorização da mensagem publicitária. Já a letra, afirma Carvalho, pode apresentar rimas, repetições para fixar a ideia do anunciante. "O texto publicitário se utiliza de estratégias linguísticas, de modo a estabelecer uma personalidade para o produto, dotando-o de atributos e promovendo-o pela celebração do nome" (CARVALHO, 2002, p. 46). Ainda para o autor, "quando se trata de fixar na memória do receptor o nome de uma marca ou um slogan, associados às qualidades do produto que se deseja vender, todos os meios de insistência são considerados legítimos" (CARVALHO, 2002, p. 67) Assim, o ouvinte/espectador poderá ser seduzido pela imagem que criará do produto ou serviço em sua mente, a partir das qualidades apresentadas na letra e melodia de um jingle.

\section{Procedimentos metodológicos, dados e resultados}

Este estudo caracteriza-se como sendo de natureza descritiva com uma abordagem qualitativa. Por meio de uma amostragem não probabilística por conveniência, foram selecionados habitantes do litoral norte de Santa Catarina, com idades entre 28 a 47 anos. A coleta de dados consistiu em entrevistas feitas pessoalmente com pessoas nascidas nas décadas de 1970 e 1980, especificamente moradores das cidades de Balneário Camboriú, Itajaí e Itapema, no estado de Santa Catarina.

Foram realizadas 46 entrevistas mediadas por um roteiro semiestruturado com perguntas relacionadas à lembrança que os entrevistados possuem em relação aos jingles veiculados durante sua infância. Para tanto, optou-se por não reproduzir nenhum áudio no momento da 
entrevista, isto é, não executar nenhum jingle, para que as respostas representassem um fiel resgate à memória de cada respondente.

As entrevistas foram realizadas com pessoas desconhecidas pelos pesquisadores para que não houvesse nenhum tipo de envolvimento. A captação das vozes foi realizada com o auxílio de um gravador de áudio, possibilitando o posterior acesso aos detalhes dos depoimentos dos entrevistados. Esses depoimentos foram transcritos e as anotações realizadas em diário de campo com os pontos considerados relevantes para a investigação.

A respeito dos jingles recordados, das 46 pessoas entrevistadas, 6 não lembraram de nenhum jingle, por simples esquecimento ou até mesmo por não possuírem na época de sua infância contato com aparelhos de televisão ou de rádio. Entretanto, houve pessoas que não conseguiram escolher especificamente um único jingle, e acabaram citando entre 3 a 4 anúncios.

Os mais citados foram o jingle da Faber-Castell, com o tema "Aquarela" de 1983 e o do Guaraná Antarctica, com o tema "Pipoca com Guaraná" de 1991, mencionados por 21,73\% dos entrevistados. Entre as justificativas pela recordação estão o fato de a Faber-Castell trabalhar os produtos com "uma música muito bonita e emocionante", e de o anúncio "mexer muito com cores e desenhos". O anúncio original 1983 deu lugar a uma nova versão em 1995 ambos cantados por crianças.

Figura 1 - Captura de tela do anúncio "Aquarela" da Faber-Castell de 1983

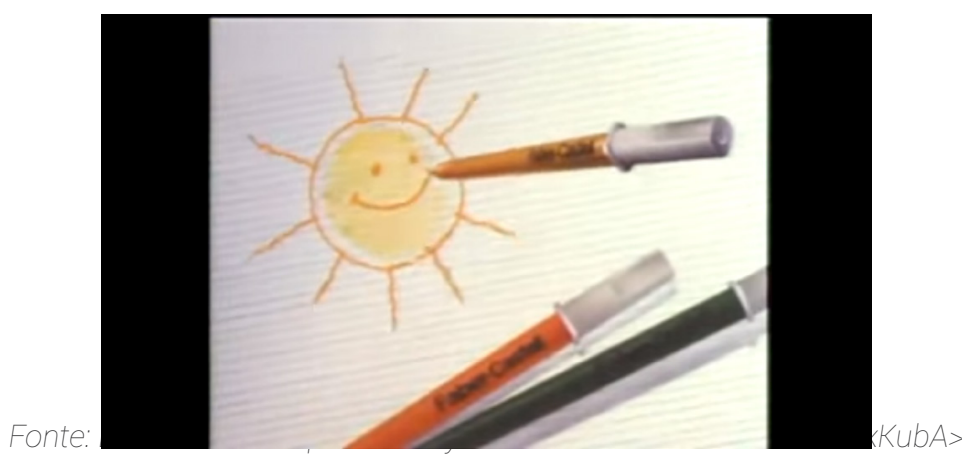

Já no jingle do Guaraná Antarctica, a justificativa mais presente nas respostas foi o a combinação dos produtos pipoca e guaraná. Os entrevistados mencionaram que sempre assistiam a filmes com pipoca e o citado refrigerante e o que mais gostavam no anúncio era o jingle em si, pois a melodia e a letra eram "muito agradáveis de escutar e cantar".

Figura 2 - Captura de tela do anúncio com o jingle "Pipoca e Guaraná" de 1991.
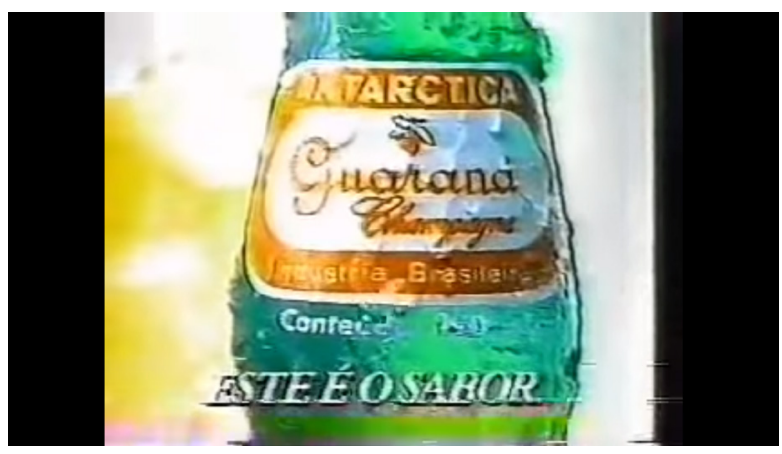

Fonte: Extraído de <https://www.youtube.com/watch?v=0_697WvD9XU> 
Além dos anúncios mencionados, foram citados outros dois jingles por 6,52\% das pessoas: os jingles "Big Mac" da rede McDonalds (1987) e "Mamíferos" da Parmalat (1996). As justificativas apresentadas pelos entrevistados foi, com relação ao primeiro, pelo fato de gostarem do lanche, o jingle era gostoso de cantar e, também, devido à promoção na qual o público que decorasse todos os ingredientes e cantasse o jingle para os atendentes no balcão receberia - lanche gratuitamente. O segundo anunciante, de forma similar, possuía, na época, uma promoção na qual os consumidores poderiam colecionar bichos de pelúcia alusivos à marca. No anúncio para televisão, inclusive, o elenco baseava-se em crianças vestidas de filhotes de animais, conforme a figura 3 .

Figura 3 - Captura de tela do anúncio televisivo com o jingle "Mamíferos" da Parmalat de 1996.

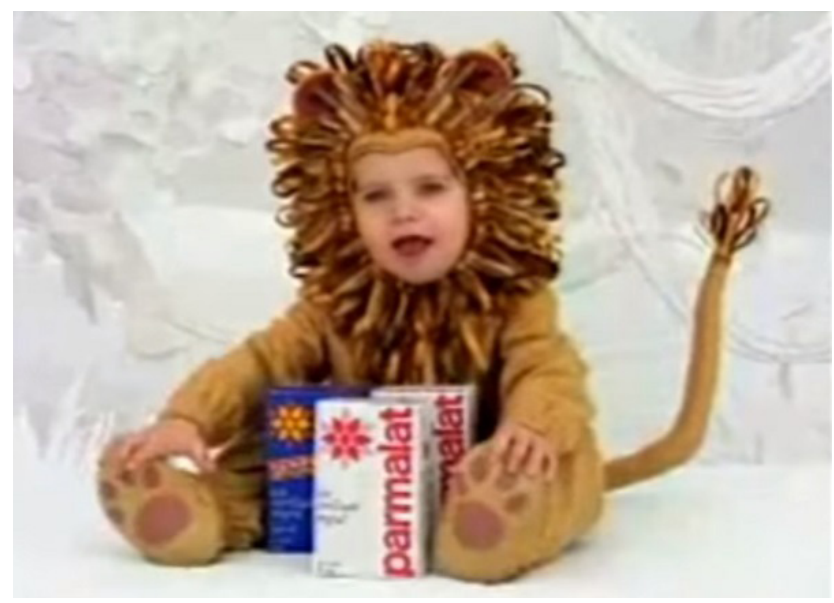

Fonte: Extraída de <https://Www.youtube.com/watch?v=tL-LJdX9Ur8>

Sampaio (2000) nos lembra os motivos do uso de crianças na publicidade, alegando que as mesmas ficam mais atentas e influenciáveis ao assistirem a algum anúncio com elenco infantil. Nesse caso, a criança transmite um forte apelo emocional, ganhando a aprovação do público por meio da sua sensibilização. Para a autora, ainda, ao se trabalhar com um elenco infantil, a marca do anúncio rejuvenesce naturalmente.

Foi observado que pessoas entre 28 a 35 anos lembraram de jingles mais recentes, da década de 1990. Alguns dos entrevistados dessa faixa etária, entretanto, mencionaram jingles dos anos 2000, como o da cerveja Brahma, cuja personagem principal é uma simpática tartaruga. Já as pessoas entre 40 a 47 anos relembraram de jingles mais antigos, como o das Casas Pernambucanas, com o título "Não adianta bater", de 1967. Outro bastante mencionado foi o do anunciante Bala de Leite Kids, com o jingle "Roda", de 1978, décadas anteriores ao escopo dessa pesquisa.

Ao serem questionadas sobre os motivos que as levaram a lembrar especificamente do jingle mencionado, grande parte das respostas foi baseada na quantidade de vezes na qual o anúncio era executado na televisão e no rádio; pelo produto estar sempre presente no dia a dia dessas pessoas e, também, pelos entrevistados se identificarem com a marca e o produto que estava sendo anunciado. Outro fato citado é que gostavam do anúncio em si, não somente do jingle mas de sua estética, por acharem engraçado, divertido, emocionante e irreverente. Algumas pessoas não sabiam ao certo o porquê de terem lembrado do jingle mencionado, outras explicaram que lembraram pelo fato de, até hoje, cantarem para filhos e sobrinhos. 
A terceira pergunta da entrevista questionava a lembrança da letra ou parte dela. Os resultados apontam que 21,73\% das pessoas não lembraram de nenhuma parte do respectivo jingle, ao contrário dos outros 78,26\%. Dentre a maioria, em vez de lembrarem especificamente da letra, lembraram da estética do anúncio ou mesmo de falas que compunham o mesmo.

Quando questionados sobre como se sentiam ao relembrarem os jingles, muitos respondentes relataram que se sentiam "felizes", por estarem relembrando algo que estava muito conectado com a infância, o que fazia se sentirem "extremamente nostálgicos". Alguns deles relataram que se sentiam "velhos", por estarem voltando para uma outra década, mas que possuíam "lembranças boas".

A questão seguinte foi em relação às lembranças mais marcantes que os entrevistados possuíam e que pudessem ser relacionadas ao jingle. Entre as respostas daquelas que recordam um jingle, a maioria tinha relação com a "família e amigos". Citaram momentos que eram dedicados à família como o período da noite, quando "todos sentavam para assistir à televisão" ou "fazer brincadeiras com os primos", nas quais simulavam a reprodução do anúncio. No caso do jingle "Pipoca e Guaraná", praticamente todos os respondentes que recordaram do anúncio citaram cenas da família assistindo à TV consumindo pipoca com refrigerante, com os pais e os irmãos.

Ao serem questionados por qual meio de comunicação os entrevistados foram impactados com os jingles de sua infância, 47,82\% das pessoas informaram que possuíam contato com a televisão e o rádio, 43,47\% possuíam mais contato somente com a televisão e 8,69\% somente com o rádio. As pessoas que tinham mais contato apenas com a televisão eram pessoas mais novas, entre 28 e 36 anos. Acima desta idade, as pessoas possuíam contato mais próximo dos dois meios de comunicação, televisão e rádio. Algumas delas completaram suas falas, com "às vezes escutava rádio, mas era apenas com meus pais. A televisão era mais presente no meu dia a dia". Pessoas entre 43 e 47 anos responderam que só tinham acesso ao rádio, por morarem em sítios ou regiões interioranas, sem aparelho de televisão em suas casas.

Um fato interessante a ser mencionado é o de que os entrevistados que não se recordaram de nenhum jingle justificaram sua falta de memória por não possuírem contato com nenhum tipo de mídia eletrônica. Pelo fato de não habitarem áreas urbanas, passavam os dias ajudando seus pais nas tarefas diárias ou costumavam brincar com seus amigos na rua. Para Sampaio (2009), o contato que a criança dispõe com os meios de comunicação não depende apenas de aspectos tecnológicos ou da linguagem; a situação econômica e o poder aquisitivo das famílias implicam no acesso limitado a diversas mídias. Nas respostas, os entrevistados que explicaram o motivo de não terem lembrado de nenhum jingle da sua época de infância alegaram ter origem mais humilde, na qual os pais não possuíam acesso aos receptores de rádio e televisão.

A respeito dos programas aos quais os entrevistados costumavam assistir quando crianças, 78,26\% responderam que assistiam a desenhos, mantendo contato frequente com programas infantis como Xou da Xuxa, Programa da Eliana, Angélica e Bom dia e Cia. Quanto às novelas, 17,39\% assistiam regularmente a esse tipo de programa. Finalmente, telejornais ou noticiários foram lembrados por 4,34\% dos entrevistados, ao mencionarem que assistiam quando crianças, porém sempre acompanhados pelos pais.

A última pergunta era sobre o controle exercido pelos responsáveis sobre os entrevistados. Para Sampaio (2009, p. 12), "o tipo de acompanhamento doméstico efetuado (ou não) por pais ou parentes - a restrição do tempo da exposição às mídias, a limitação do acesso a 
determinados conteúdos e/ou o diálogo sobre cenas e acontecimentos - também é um elemento demarcador". Na análise das respostas, 34,78\% alegaram que eram supervisionados com relação ao horário no qual assistiam à televisão, principalmente a partir das 20 horas, momento de transmissão do noticiário, pois "já deveriam estar na cama dormindo". Outros mencionaram que assistiam ao noticiário e novelas, mas apenas com os seus pais ou responsáveis. Por outro lado, 56,52\% dos entrevistados declararam não existir qualquer tipo de controle por parte de seus responsáveis, podendo assistir a qualquer tipo de programação durante o tempo que quisessem.

Como panorama da investigação, nota-se uma influência preponderante nos anúncios audiovisuais com relação aos jingles mais recordados, com fortes apelos visuais, melodias marcantes e redação simples em suas letras. A constante exposição aos programas de desenhos animados também pode ter acarretado uma maior frequência de impacto de anúncios publicitários nos entrevistados, sendo o controle por parte dos pais inexistente em mais da metade dos participantes da pesquisa. Os resultados revelam, sobretudo, que os jingles trazem consigo mais do que uma finalidade exclusivamente persuasiva, mas também um significativo impacto emocional, perdurando de forma singular na memória dos consumidores.

\section{Considerações Finais}

Esta pesquisa teve como objetivo analisar a influência dos jingles dos anos 1980 e 1990 em pessoas que, nessas décadas, eram crianças. Constatou-se que a maioria dos entrevistados não possuía condições financeiras para consumir os produtos e serviços, mas que recordavam de momentos em família e amigos, com brincadeiras que faziam alusão a determinado jingle. com base nesses resultados, a maioria foi impactada emocionalmente, com o jingle fazendo parte da infância dessas pessoas de uma forma afetiva e não exclusivamente comercial.

Um fato interessante a ser mencionado é que algumas pessoas não sabiam ao certo o que era um jingle, confundindo-o com músicas de autoria de artistas famosos ou até mesmo com anúncios não-musicados. Portanto, como as entrevistas foram realizadas presencialmente, foi importante o esclarecimento para que não houvesse nenhum tipo de mal-entendido ou interpretação equivocada.

Como não foi apresentado nenhum áudio com jingles pré-selecionados a intenção da pesquisa foi extrair a essência dos entrevistados e minimizar a possibilidade de influência na hora das respostas. Por isso, alguns entrevistados que não lembraram de nenhum jingle no momento da entrevista comentaram que seria mais fácil para eles se antes das perguntas fosse mostrado algum exemplo. Um estudo futuro, portanto, poderia trazer outras percepções baseadas nessa metodologia.

\section{Referências}

ALVES, Marcia Nogueira; FONTOURA, Mara; ANTONIUTTI, Cleide Luciane. Mídia e produção audiovisual: uma introdução. Curitiba: IBPEX, 2008.

CALAZANS, Flávio. Propaganda subliminar multimídia. São Paulo: Summus, 2006.

CARVALHO, Nelly de. Publicidade: a linguagem da sedução. $3^{a}$ ed. São Paulo: Ática, 2002. 
FIGUEIREDO, Celso. Redação publicitária: sedução pela palavra. São Paulo: Pioneira Thomson, 2005

PACHECO, Elza D. Televisão, criança, imaginação e educação. Campinas: Papirus, 2002.

PÉREZ-NEBRA, Amalia R., SANTANA, Ana F. R. "Será que imagem é mesmo tudo?" Descrição de variáveis que impactam a retenção da propaganda na memória. In: Comunicação \& Inovação, São Caetano do Sul, v. 9, n. 17:(13-24) jul-dez 2008.

RODRIGUEZ, Angel. A dimensão sonora da linguagem audiovisual. São Paulo, SP. SENAC São Paulo, 2006.

SAMPAIO, Rafael. Propaganda de A a Z: como usar a propaganda para construir marcas e empresas de sucesso. $3^{a}$ ed. Rio de Janeiro: Campus, 2003.

SAMPAIO, Inês S. V. Televisão, publicidade e infância. São Paulo: Annablume, 2000.

Infância e consumo: estudos no campo da comunicação. In: Publicidade e Infância: uma relação perigosa. Brasília, 2009. cap. 01, p. 09 - 21.

SOUZA JÚNIOR, José E. G.; FORTALEZA, Camila H.; MACIEL, Josemar. Influência e consumo: estudos no campo da comunicação. In: Publicidade Infantil: o estímulo à cultura de consumo e outras questões. Brasília, 2009, p. 22-34.

Recebido: 07/05/2018

Aceito: 07/05/2019 